\title{
Influencing factors of REY enrichment in the sediments from the central Pacific: new insight from in-situ neodymium isotopes of fish debris \\ FENLIAN WANG ${ }^{1,2}$ GAOWEN HE ${ }^{1,2}$ \\ ${ }^{1}$ MLR Key Laboratory of Marine Mineral Resources, Guangzhou Marine Geological Survey, Guangzhou 510760, China.E-mail address: fenlian0523@163.com \\ ${ }^{2}$ Southern marine science and Engineering Guangdong Laboratory, Guangzhou, 510301, China.
}

Apatite (fish debris) is the main REY(REE+Y) host phase of the REY-rich mud in the Central Pacific. Neodymium isotopes from apatite became a powerful method to trace provenance of REE and reconstruct ocean circulation. In this study, in situ neodymium isotopes of fish debris from 41 different depth interval sediments were obtained for PC01 in the central Pacific. Our data show that ${ }^{143} \mathrm{Nd} /{ }^{144} \mathrm{Nd}$ ratios of apatites vary from $0.512136 \sim 0.512533$, corresponding to a $\varepsilon_{\mathrm{Nd}}$ range from -9.8 to -2.04 . However, there are clear vertical variations in the $\mathrm{Nd}$ isotopes of apatites from the sediments. The $\varepsilon_{\mathrm{Nd}}$ signals from the lower-REY values $(<1000 \mathrm{ug} / \mathrm{g})$ sediments in the $0 \sim 2$ meters and 5 meters to the bottom are around -5 -3, similar to $\varepsilon_{\mathrm{Nd}}$ values of the deep-seawater in the North-Central Pacific, indicating that REE in these sediments mainly come from seawater.

The $\varepsilon_{\mathrm{Nd}}$ values of apatites from the rich-REY values $(>1000 \mathrm{ug} / \mathrm{g})$ sediments in the 2 5 meters range from 9.8 -4.17, mostly around -8 -7. The potential sources and input mechanisms of lower $\varepsilon_{\mathrm{Nd}}$ values include: (1) terrestrial inputs characterized by unradiogenic $\varepsilon_{\mathrm{Nd}}$; (2) mixing with other waters.

However, the sediments at 2 5 meters of PC01 have lower $\mathrm{Al}_{2} \mathrm{O}_{3}$ and $\mathrm{SiO}_{2}$ than the other sediments, indicating that the lower $\varepsilon_{\mathrm{Nd}}$ is not caused by the terrestrial inputs. The $\varepsilon_{\mathrm{Nd}}$ values of apatites from the rich-REY values is close to the $\varepsilon_{\mathrm{Nd}}$ values of Antarctic Bottom Water $(\mathrm{AABW}, \approx-9)$ and we noted that the area of PC01 may be influenced by AABW. Therefore, we largely support the idea that the unradiogenic $\varepsilon_{\mathrm{Nd}}$ is most likely the result of influence of AABW. That is to say, AABW may play a very important role in the enrichment of REY in the sediment from the central Pacific. 